\section{Matéria \\ ISSN 1517-7076}

Revista Matéria, v. 15, n. 2,pp. 138-142, 2010.

http://www.materia.coppe.ufrj.br/sarra/artigos/artigo11207

\title{
Titanium dental implant surfaces
}

\author{
Carlos Nelson Elias \\ Laboratório de Biomateriais- IME, CP: 22290-270, Rio de Janeiro, RJ. \\ e-mail: elias@ime.eb.br
}

\begin{abstract}
Osseointegration has been defined as "a direct structural and functional connection between ordered, living bone and the surface of a load-carrying implant". However, titanium and its alloys cannot directly bond to living bone after being implanted into the body. The osseointegration of titanium dental implants is critically dependent on the implant surface properties. Various surface modifications have been proposed in order to provide commercially pure titanium with bioactive bone bonding ability. In the present work, the titanium dental implant surface morphology was modified by acid etching and electrochemical treatments with the purpose of enhancing tissue response, and decreasing the waiting time for implant loading. The results show that surface morphology, topography, roughness and chemical composition were changed by the treatments and these changes has a significant influence on osseointegration. The best results were observed in the samples submitted to the electrochemical treatment.
\end{abstract}

Keywords: Dental implant; anodized implant, acid etched.

\section{INTRODUCTION}

The aim of modern dentistry is restore contour, function, esthetic, speech, and oral health, regardless of atrophy, disease, or injury of the stomatognatic system [1]. However, the more teeth a patient is missing, more difficult is the treatment and the results are unexpected with traditional dentistry. Current trends in clinical dental implant therapy include use of endosseous dental implants.

The high success rate of titanium dental implants has been attributed to formation of a direct boneimplant interface with no intervening soft tissues [2]. However, treatment of jaws with advanced resorption and poor bone quality presents a high rate of implant failure. One way to decrease this clinical problem is to use a dental implant with a treated surface. It has been suggested that physiochemical and dielectric properties, crystal structure and surface morphology of titanium oxide films on dental implant surfaces play a crucial role in the biocompatibility and osseointegration of implants [근 $\underline{5}$. Consequently, numerous modifications for dental implants have been proposed and carried out to improve surface quality and to obtain the most biocompatible implant surface.

Studies have shown that $\mathrm{Ti}$ implants with adequate roughness may enhance bone-to-implant contact [6] and increase the removal torque force [7-9]. Elias et al. [10] analyzed different methods for increasing surface roughness and improving dental implant osseointegration. The morphologies of implant surfaces subjected to sandblasting, acid etching, laser treatment, and anodizing have been analyzed. When the applied voltage reaches a certain value, a micro-arc occurs as a result of the dielectric breakdown of the $\mathrm{TiO}_{2}$ layer. When this happens, $\mathrm{Ti}$ ions in the implant and $\mathrm{OH}$ ions in the electrolyte move very quickly in opposite directions to form $\mathrm{TiO}_{2}$ again. This newly formed $\mathrm{TiO}_{2}$ layer incorporates $\mathrm{Ca}$ and $\mathrm{P}$ ions into the surface layer [11]

The implant surface roughness also affects the primary stability of dental implants [12]. Some mechanisms involved in osseointegration depend on whether the implant surface is smooth or rough, since cells react differently to these conditions. Fibroblasts and epithelial cells adhere more strongly to smooth surfaces, whereas osteoblastic proliferation and collagen synthesis are enhanced in rough surfaces [13, 14].

According to Sul $[\underline{14}, \underline{15}]$, the healing process around a dental implant with a treated surface occurs through a gradual mineralization process from the old bone to the implant surface. The healing time for dental implants without any surface treatment is longer than for implants with surface treatments. In order to reduce the mineralization time for implant osseointegration, surface treatments are performed to increase the implant surface cell adhesion and improve the osseointegration mechanisms [10]. The exact influence of chemical surface composition and morphology during the initial osseointegration stage is not well known. 
It was observed that dental implants with adequate surface roughness have improved osteoanchorage and biomechanical stability [13]. An anodized implant surface with calcium phosphate incorporated into the titanium oxide crystal structure improves the healing process, allowing a faster biological fixation of implants. The literature [16] shows that dental implants with anodized surfaces present a good clinical prognosis (95\% success in five years).

The purpose of the present work is to investigate the surface chemistry and crystal structure of a titanium oxide layer on acid etched and anodized implants. The samples were characterized by scanning electron microscopy, thin-film X-ray diffraction and X-ray photoelectron spectroscopy.

\section{MATERIALS AND METHODS}

Two groups of commercially pure (cp) titanium dental implants and disks were studied in the present work. Group 1 consisted of acid etched implants such as the surface commercially known as Master Porous Implant $^{\circledR}$ (Conexão Sistemas Prótese, Brazil). The screw-type dental implant surfaces in Group 2 are anodized such as the surface commercially known as Vulcano Actives ${ }^{\circledR}$ (Conexão Sistemas Prótese, Brazil). All implants were machined from bars of ASTM titanium grade 4. The acid etched dental implants were immersed in a mixture of $\mathrm{HNO}_{3}, \mathrm{HCl}$ and $\mathrm{H}_{2} \mathrm{SO}_{4}$. The anodized samples were prepared using micro-arc oxidation methods at high anodic forming voltages and current densities in the galvanostatic mode. A mixed electrolyte containing $\mathrm{Ca}$ and $\mathrm{P}$ was used. After surface treatment, the samples were rinsed with distilled water, dried in an air furnace at $70{ }^{\circ} \mathrm{C}$ for $2 \mathrm{~h}$, packed and sterilized with gamma radiation ( 25 kgray). The electrochemical micro-arc oxidation method has been described in previous studies $[11,14,15]$.

The surface morphology and composition was investigated by scanning electron microscopy and Xray photoelectron spectroscopy. For the analysis of the titanium oxide crystal structures, thin-film X-ray diffraction was conducted at $40 \mathrm{kV}$ and $30 \mathrm{~mA}(\mathrm{Cu}-\mathrm{K} \alpha=1.542 \AA)$, with a step size of 0.02 degree $/ \mathrm{min}$.

Discs of Ti were cut from the same bar used to manufacture the dental implants and submitted to the same treatment. The surface roughness of the samples was quantified using an optical laser profilometer (Mahr GmbH, Gottingen, Germany). The measured roughness parameters were the arithmetic average of the absolute values of all points of the profile (Ra), the root mean square of the values of all points (Rq), the average value of the absolute heights of the five highest peaks and the depths of the five deepest valleys (Rz).

Six screw-shaped implants $6 \mathrm{~mm}$ long and $3.75 \mathrm{~mm}$ in diameter from each group were inserted in rabbit tibia. After a healing period of four weeks the torque necessary to loosen the implants from the tibia was measured.

\section{RESULTS}

Scanning electron micrographs of the surfaces of acid etched and anodized dental implants are shown in Fig 1.

The acid etched implants have a homogeneous surface. The surface morphology of anodized implant is characterized by small craters with holes at the center, like a volcano.

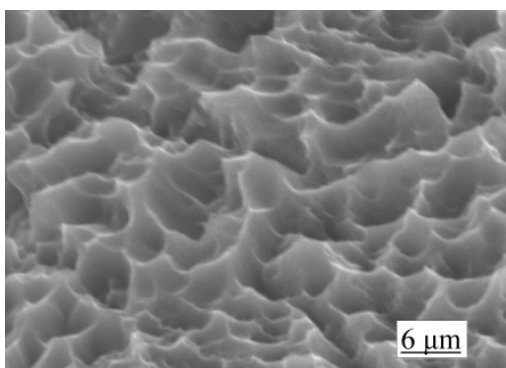

(a)

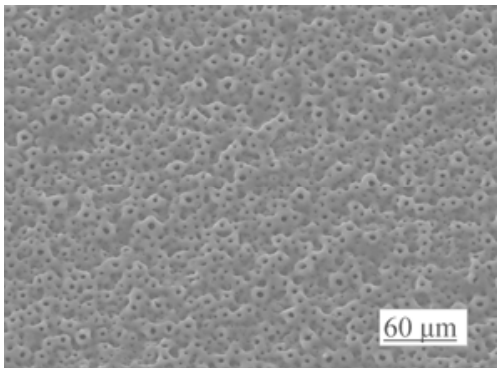

(b)

Figure 1: Titanium dental implant surface morphology. (a) Acid etched. (b) Anodized.

Table 1 shows the roughness parameters for both groups of samples. The surface roughness parameter $\mathrm{R}_{\mathrm{a}}$ for Group 2 samples is larger than for Group 1 samples. One can see that the average roughness $\left(R_{a}\right)$ has a significant influence on the minimum torque to remove the implant. The other parameters used to quantify the degree of roughness are the quadratic average roughness $\left(R_{q}\right)$, the peak-to-valley roughness $\left(R_{z}\right)$, and maximum roughness height $\left(\mathrm{R}_{\max }\right)$. Although the parameter $\mathrm{R}_{\mathrm{a}}$ will not always be useful to characterize the morphology of a surface, it is widely used because no other roughness parameter is known to better describe and predict implant behavior. Doubts exist as to whether the height of surface irregularities is more 
important than the distance between them and which combination of these factors could improve osseointegration.

Table 1: Dental implant roughness parameters and torque to remove from rabbit tibia.

\begin{tabular}{l|l|l|l|l|l}
\hline Surface & $\mathrm{R}_{\mathrm{a}}(\mu \mathrm{m})$ & $\mathrm{R}_{\mathrm{q}}(\mu \mathrm{m})$ & $\mathrm{R}_{\mathrm{z}}(\mu \mathrm{m})$ & $\mathrm{R}_{\max }(\mu \mathrm{m})$ & Torque $(\mathrm{N} \cdot \mathrm{cm})$ \\
\hline Acid etched & $0.51 \pm 0.10$ & $0.71 \pm 0.07$ & $5.09 \pm 0.46$ & $6.78 \pm 1.33$ & $75.4 \pm 10.5$ \\
\hline Anodized & $0.87 \pm 0.14$ & $1.12 \pm 0.18$ & $5.14 \pm 0.69$ & $19.84 \pm 2.13$ & $83.1 \pm 12.7$ \\
\hline
\end{tabular}

Figure 2 shows X-ray photoelectron spectroscopy spectrum of one of the dental implant samples from Group 2. These spectra suggest that the outermost surface oxide layer of the micro-arc oxidation implant consists mainly of titanium dioxide. The anodized implants contained $\mathrm{Ca}$ and $\mathrm{P}$ electrochemically incorporated into the titanium oxide matrix. The $\mathrm{Ca}$ and $\mathrm{P}$ in the oxide layer came from the electrolyte solution used in the micro-arc oxidation process.

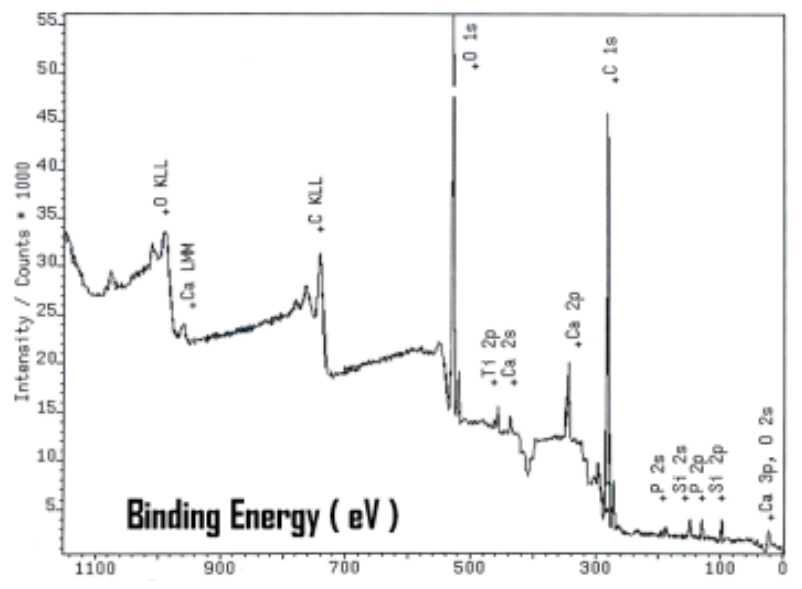

Figure 2: X-ray photoelectron spectroscopy spectrum of an anodized implant.

XRD spectra of etched samples showed peaks of Ti. The X-ray diffraction spectrum of an anodized sample is displayed in Figure 3 and shows the presence of titanium oxide in the rutile and anatase crystalline forms, apparently with higher anatase phase content than rutile.

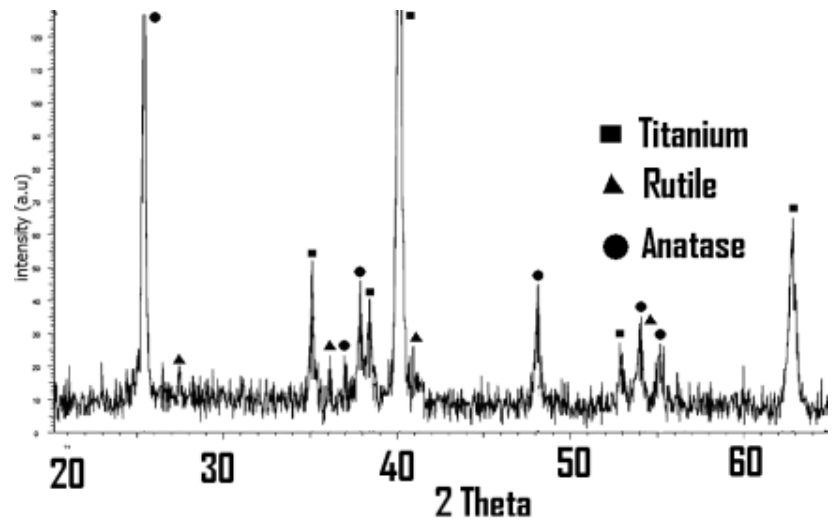

Figure 3: X-ray diffraction spectrum of an anodized sample. 


\section{DISCUSSION}

The differences between commercially available implants can involve roughness, chemical composition, surface energy, chemical potential, presence of hydrates and nitrates, layers with residual stress, impurities resulting from manufacturing or handling procedures, types of titanium oxide and thickness of the oxide layer. Analysis of these differences is important, since proteins interact with the oxides on implant surfaces. Doubts exist about the optimal procedure for obtaining the best biological response to dental implants. The implant design and the surface morphology are known to be two important properties for implant success. When the importance of the implant surface properties for osseointegration is analyzed, one should separate the influences of implant design and surface morphology. In the present work only the influence of implant surface on the removal torque was analyzed.

Acid treatment provides homogeneous roughness, a large active surface area, and improved bioadhesion. The morphology of the implant surface shown in Fig. 1 is isotropic and exhibits microcavities with defined edges. This type of surface not only facilitates retention of osteogenic cells but also allows them to migrate towards the implant surface. Implants having a surface morphology similar to that induce fibrin retention, favor adsorption of fibronectin and facilitate osseointegration [17].

The purpose of an anodizing treatment is to change the morphology and chemical composition of the titanium oxide layer by adding $\mathrm{Ca}$ and $\mathrm{P}$ to the surface. The layers produced by this treatment are rich in $\mathrm{Ca}$ and $\mathrm{P}$, which accelerate the osseointegration process. According to the results of the present work, the titanium oxide layer formed in all implants prepared using the micro-arc oxidation method incorporated $\mathrm{Ca}$ and $\mathrm{P}$ from the electrolytic solution.

Previous studies have shown a surface enrichment of $\mathrm{Ca}$ and $\mathrm{P}$ and the presence of rutile and anatase in the anodized surface [10]. Li et al. [11] observed that at low voltage the dominant $\mathrm{TiO}_{2}$ phase is anatase. For larger voltages, the rutile phase is also detected in significant amounts.

The results of removal torque in this study agree with previous results of in vivo studies with Vulcano Actives ${ }^{\circledR}$ in rabbits [10]. The removal torque of anodized dental implant is higher than for acid etched implants. It was observed that in both cases induction of bone growth at the implant interface was effective, decreasing the time required for implant loading. The tissue response to micro-arc oxidation implants is not fully understood. Sul et al. [15] investigated the influence of the $\mathrm{Ca}$ ion on titanium surfaces implanted in rabbit bone. They observed that the bone response may be dependent on the $\mathrm{Ca}$ concentration and is possibly related to the formation of an electrostatic bridge between the titanium surface and adhesive biomolecules in the extracellular bone matrix.

All the dental implants studied in the work showed osseointegration. Since anodized and acid etched implants with the same design behaved differently, the results suggest that the kind of surface treatment has a significant influence on the interaction of the implants with cells and vital bone tissue. Osseointegration is favored by $\mathrm{Ca}$ and $\mathrm{P}$ enrichment of the oxide layer.

\section{CONCLUSIONS}

The results of the present work show that:

1. Surface treatment of dental implants can change the chemical composition and morphology of the surface;

2. The micro-arc oxidation method induces the formation of the anatase phase of titanium oxide and also incorporates $\mathrm{Ca}$ and $\mathrm{P}$;

3. Anodized dental implants exhibit a higher removal torque than acid etched implants.

\section{ACKNOWLEDGMENTS}

This work was supported by grants from the Brazilian government: Conselho Nacional de Pesquisa e Desenvolvimento (Processes 472449/2004-4, 400603/2004-7 and 500126/2003-6), Conexão Sistema e Prótese and Fundação de Amparo a Pesquisa do Estado do Rio de Janeiro (Process E-26/151.970/2004).

\section{REFERENCES}

[1] MISCH, C.E., Contemporary Implant Dentistr, Mosby Year Book Co, St Louis, 2007.

[2] BRANEMARK, P.I., ADELL, R., BREINE, U., et al., "Intra-osseous anchorage of dental prostheses: I. experimental studies", Scandinavian Journal of Plastic and Reconstructive Surgery, v 3, pp. 81-100, 1969. 
[3] BOWERS, K., KELLER, J., RANDOLPH, B., et al. "Optimization of surface micromorphology for enhanced osteoblast responses in vitro", International Journal of Oral Maxillofac Implants, v. 7, pp. 302-310, 1992.

[4] MARTIN, J., SCHWARTS, Z., HEMMERT, T., et al., "Effect of titanium surface roughness on proliferation, differentiation, and protein synthesis of human osteoblast-like cells (MG63)", Journal of Biomedical Material Research, v. 29, pp. 389-401, 1995.

[5] COCHRAN, D., SCHENK, R., LUSSI, A., et al. "Bone response to unloaded and loaded titanium implants with sandblasted and acid-etched surface: A histometric study in the canine mandible". Journal of Biomedical Material Research, v. 40, pp. 1-11, 1998.

[6] WENNERBERG, A., “On surface roughness and implant incorporation”, Ph.D. Thesis, 1996.

[7] SUL, Y.T., JOHANSSON, C.B., JEONG, Y., WENNERBERG, A., ALBREKTSSON, T., "Resonance frequency and removal torque analysis of implants with turned and anodized surface oxides", Clinical Oral Implants Research, v. 13, n. 3, pp. 252-259, 2002.

[8] WENNERBERG, A., EKTESSABI, A., ALBREKTSSON, T., JOHNANSSON, C., ANDERSSON, B.A., "1-year follow-up of implants of differing surface roughness placed in rabbit bone", International Journal of Oral Maxillofac Implants, v. 12, n. 4, pp. 486-494, 1997.

[9] KLOKKEVOLD, P.R., NISHIMURA, R.D., ADACHI, M., CAPUTO, A., “Osseointegration enhanced by chemical etching of the titanium surface. A torque removal study in the rabbit", Clinical Oral Implants Research, v. 8, n. 6, pp. 442-447, 1997.

[10] ELIAS, C.N., OSHIDA, Y., LIMA, J.H.C., MULLER, C.A., "Relationship between surface properties (roughness, wettability and morphology) of Ti and dental implant removal torque", Journal of the Mechanical Behavior of Biomed Materials, v. 1, pp. 234-42, 2008.

[11] LI, L.H., KONG Y.M., KIM, K.W., et al., "Improved biological performance of Ti implants due to surface modification by micro-arc oxidation”, Biomaterials, v. 25, pp. 2867-2875, 2004.

[12] SANTOS, M.V., ELIAS, C.N., LIMA, J.H.M.C., "The effects of superficial roughness and design on the primary stability of dental implants", Clinical Implant Dental Relat Research, DOI 10.1111/j.17088208.2009.00202.x, 2009.

[13] BOYAN, B.D., DEAN, D.D., LOHMANN, C.H., "The titanium bone cell interface in vitro: The role of the surface in promoting osteointegration", In: Titanium in Medicine, Brunette, D.M, Tengvall, P., Textor, M., Thomsen, P. (Eds), Spinger Verlag, Berlin, 2001.

[14] SUL, Y.T., "The significance of the surface properties of oxidized titanium to the bone response: special emphasis on potential biochemical bonding of oxidized titanium implant", Biomaterials, v. 24, pp. 3893-907, 2003.

[15] SUL, Y.T., JOAHANSSON, C.B., JEONG, Y., ALBREKTSSON, T., "The electrochemical oxide growth behavior on titanium in acid and alkaline electrolytes", Medical Engineering \& Physics, v. 23, pp. 329-346, 2001.

[16] ZHANG, Y.M., BATAILLON-LINEZ, P., HUNAG, P., et al., "Surface analyses of micro-arc oxidized and hydrothermally treated titanium and effect on osteoblast behavior", Journal of Biomedical Material Research, v. 68A, pp. 383-391, 2004.

[17] BRACERAS, I., DE MAETZU, M.A., ALAVA, J.I., GAY-ESCODA, C., "In vivo low-density bone apposition on different implant surface materials", International Journal of Oral Maxillofac Surgery, v. 38, n. 3, pp. 274-278, 2009. 